\title{
Prospective, cross-sectional study on MSSA and MRSA colonisation in hospitalised children
}

\author{
Kristen Johnson ${ }^{1,2} \cdot$ Reno Frei $^{3} \cdot$ Ulrich Heininger $^{1,2}$
}

Received: 27 May 2015 / Revised: 21 July 2015 / Accepted: 26 July 2015 / Published online: 15 August 2015

(C) Springer-Verlag Berlin Heidelberg 2015

\begin{abstract}
There is a global trend for an increase in prevalence of nasal methicillin-resistant Staphylococcus aureus (MRSA) colonisation in children. A decade ago, MRSA colonisation was studied in Swiss paediatric hospitals and revealed an extraordinarily low proportion $(<1 \%)$. The primary goal of this study was to determine if the current proportion of nasal colonisation with MRSA in hospitalised children was still favourable. We aimed to screen all children from the age of $0-16$ years admitted to the paediatric and surgical wards at the University Children's Hospital Basel (UKBB) during 8 predefined surveillance weeks. After obtaining consent, a nasal swab was taken and analysed for growth of S. aureus. Furthermore, a standardised questionnaire was completed by interview with a parent. Of 535 eligible children, $340(64 \%)$ were enrolled. Mean age was 6.2 years (median 4.3, IQR 1 to 11.25), 111 (33\%) children were colonised with S. aureus but no MRSA was found.

Conclusion: The prevalence of MRSA in children admitted to the UKBB during this surveillance period was zero.
\end{abstract}

Communicated by David Nadal

Ulrich Heininger

ulrich.heininger@ukbb.ch

Kristen Johnson

kristen.johnson@stud.unibas.ch

Reno Frei

reno.frei@usb.ch

1 University Children's Hospital, Spitalstrasse 33, PO Box, CH 4031 Basel, Switzerland

2 University of Basel, Basel, Switzerland

3 Clinical Microbiology, University Hospital Basel, Basel, Switzerland
General MRSA screening in hospitalised children continues to be unjustified in our area.

What is known:

- The prevalence of nasal methicillin-resistant Staphylococcus aureus (MRSA) colonisation in children is increasing in many regions worldwide.

- Surveillance for MRSA colonisation in healthcare settings varies considerably.

What is new:

- Periodic and risk-factor-based surveillance for MRSA colonisation is sufficient when regional prevalence is low.

Keywords Staphylococcus aureus · Colonisation · Methicillin resistant $\cdot$ MRSA $\cdot$ Child
Abbreviations
MRSA Methicillin-resistant Staphylococcus aureus
MSSA Methicillin sensitive Staphylococcus aureus
UKBB University Children's Hospital Basel

\section{Introduction}

Staphylococcus aureus is a frequent pathogen, which is able to induce a wide range of infections in humans from tame skin infections to life-threatening invasive diseases, such as infective endocarditis and sepsis [20]. An antibiotic-resistant variant of this pathogen, known as methicillin-resistant Staphylococcus aureus (MRSA), was first discovered in a study in 1960 [15]. Since then, there has been a steady increase in the prevalence of MRSA infections worldwide [5, 9, 16, 17, 21]. This has led to substantial concern within the medical 
community, as well as a significant increase in research activity to try to develop new antibiotics to combat MRSA.

In the first years after its discovery, MRSA only occurred in healthcare settings (healthcare-associated MRSA, hMRSA), whereas, healthy individuals in the communities (outside healthcare settings) were not colonised with this resistant bacterium. However, since the 1980s, an increasing number of MRSA infections was identified in the outpatient sector, now named community acquired MRSA (cMRSA) [2, 14, 19, 22].

A previous review [24] showed that there was high geographic variation in prevalence of MRSA infections, especially in Europe, and that MRSA prevalence varied almost 100fold, from $<1 \%$ in northern Europe to $>40 \%$ in southern and western Europe. This study concluded that screening initiatives needed to be intensified at all levels in order to contain the spread of the pathogen. Furthermore, it was emphasised that the screening initiatives at the regional and hospital levels would be the most effective [24].

Only very few studies have investigated the prevalence of MRSA colonisation in children in Switzerland, and the last formal study on this topic was performed in 2006 under the leadership of the University Children's Hospital Basel (UKBB) [6]. At that time, only 1 of $562 \mathrm{~S}$. aureus isolates was MRSA; it was postulated that "it will be important to continue to closely monitor the development of MRSA colonisation in our childhood population, and repetition of this study might be warranted in the future" [13]. Based on these findings, MRSA screening has been restricted to patients from foreign countries admitted to the UKBB or those who are transferred from a different hospital.

This study was commissioned to follow up on the conclusions of the earlier study, to determine whether there has been any significant change in the prevalence of MRSA colonisation in children admitted to the UKBB, and hence to evaluate whether the current screening methods utilised at the UKBB are still adequate.

\section{Methods}

This cross-sectional prospective study was conducted at the UKBB, a hospital serving the northwestern part of Switzerland, with some patients also residing in the bordering regions of Germany and France.

The main aim of this study was to assess the prevalence of $S$. aureus colonisation including testing for methicillin resistance in children admitted to the UKBB. Secondary aims were as follows:

1. Determination of risk factors for MRSA colonisation

2. Comparison of current data with those from the previous surveillance study, conducted a decade ago [13]
Recruitment was scheduled to take place in calendar weeks 32, 33, 34, 35, 45 and 46 of 2014 and calendar weeks 6 and 7 in 2015. These weeks were pre-defined according to the availability of the study coordinator (KJ).

During the surveillance weeks, newly admitted patients were identified from the hospital's electronic patient data system on a daily basis and the following inclusion criteria were assessed:

- Age 0-16 years

- Admission to the UKBB as an in-patient on the general paediatric or surgical/orthopaedic wards, regardless of medical reason

- Agreement to take part in the study through informed consent by patient (14 years of age and older) and/or parent(s)

Exclusion criteria were:

- Newborns admitted to neonatal care directly after birth

- Patients admitted directly to the intensive care unit, to the oncology ward or to the psychiatry ward

\section{- In-house transfer of patients from ward to ward}

Parents of eligible patients were then approached and informed about the study. After informed consent had been obtained, a single dry nasal swab from both nostrils was taken, put into transport medium and brought to the central microbiology laboratory (Division of Clinical Microbiology, University Hospital Basel) by the study coordinator for culture of S. aureus.

In addition, a standardised questionnaire was completed for each patient by personal interview with a parent, evaluating patient characteristics and therefore assessing possible risk factors and possible sources of transmission. Patient characteristics consisted of gender, nationality, domicile, date of admission, reason for hospitalisation, chronic underlying disease, pets, travel abroad in the 3 months prior to admission, number of previous hospitalisations as well as number of hospitalisations in the 3 months prior to admission, antibiotic use in the 3 months prior to admission (including dosage, name and duration of use, if known), previous colonisation with MRSA in the patient or in a family member, hospitalisation of a family member in the preceding 3 months and employment of a family member in a medical facility.

\section{Ethical considerations}

This study was approved by the local ethics committee (EKNZ, 2014-211) prior to the beginning of the recruitment. 


\section{Laboratory testing}

Microbiological investigations were performed using validated state-of-the-art methods.

Nasal swabs were brought to the laboratory with the use of M40 Transystem (Copan, Brescia, Italy). For culture of S. aureus, the selective Staphylococci Enrichment Broth (Axon Lab, Baden, Switzerland) was inoculated.

After overnight incubation at $37^{\circ} \mathrm{C}$, a subculture was performed on a chromogenic chromID ${ }^{\mathrm{TM}}$ MRSA plate (bioMérieux, Marcy l'Etoile, France) which was incubated for up to 48 hours. Suspect isolates were identified by use of matrixassisted laser desorption/ionisation - time of flight (MALDITOF) mass spectrometry (MALDI Biotyper, Bruker Daltonik, Bremen, Germany) according to the manufacturer's instructions. $S$. aureus isolates were checked for oxacillin resistance by use of agar diffusion method with a cefoxitin disc following the guidelines of the European Committee on Antimicrobial Susceptibility Testing (EUCAST 2014, www.eucast.org).

\section{Statistics}

Data such as gender, age and possible risk factors were entered into Excel (Microsoft Excel for Mac 2011, version 14.4.8) and descriptive and statistical analyses were performed. Statistical significance and confidence intervals were calculated by twosided Fisher's exact test. Error bars in Figs. 3 and 4 denote $95 \%$ Clopper-Pearson confidence interval. Statistical analyses were performed using Stata 13.0 (StataCorp, College Station, TX, USA).

\section{Results}

\section{General characteristics}

During the three surveillance periods, 639 patients were admitted to the hospital and 535 (84\%) of them were eligible for participation. Finally, 340 (64\%) were enrolled (Fig. 1). Countries of residence for the enrolled patients were Switzerland $(N=316 ; 93 \%)$, France $(N=13 ; 4 \%)$, Germany $(N=5$ $(1 \%))$ and others $(N=6 ; 2 \%)$.

The mean age of enrolled children was 6.21 years with a median age of 4.3 years (interquartile range (IQR) 1 to 11.25 years). The majority of enrolled children was male $(N=$ 204; $60 \%$ ). Mean age of MSSA-colonised children was 7.4 years with a median age of 7.5 years (IQR 11 months to 11 years).

The majority of study participants $(N=208 ; 61 \%)$ stayed in hospital for 2-5 days, 78 (23\%) stayed for only 1 night and 54 $(16 \%)$ were hospitalised for $>5$ days.

Of note, MSSA colonisation was higher in patients on the surgical/orthopaedic ward $(70 / 154 ; 45 \%)$ than in those on the paediatric ward $(41 / 184 ; 22 \% ; p=0.03)$.

\section{Study timeline}

Figure 2 shows the number of patients approached for the study and proportions of enrolled participants in each of the 8 surveillance weeks. As can be seen, there was a fairly even distribution of enrolment over all surveillance weeks.

\section{Results from the questionnaire and microbiologic findings}

In 111 (33\%) of 340 patients, nasal colonisation of S. aureus was found and all isolates were methicillin sensitive (MSSA). Of the 111 patients with MSSA colonisation, 93\% were from Switzerland, $4 \%$ were from France, none from Germany and $3 \%$ from other countries, i.e. proportionally to countries of residence.

In infants, MSSA colonisation proportion was $29 \%$ and declined thereafter to again increase from 4 years of age onwards with a relative peak around 8 years of age (Fig. 3). For children up to 4 months of age, the proportion of MSSA colonisation was fairly consistent in the range of approximately 30 to $40 \%$ (Fig. 4); there is less consistency beyond 4 months of age, probably due to low numbers of enrolled infants. Still, MSSA colonisation in children $<6$ months of life was higher compared to children 6-11 months of life: 20 of $56(36 \%)$ versus 4 of $28(14 \% ; p=0.045)$.

Table 1 summarises the results of the questionnaire on the general characteristics of the patients enrolled in the study; there were no significant or meaningful differences by MSSA colonisation status.

\section{Discussion}

We investigated nasal colonisation with $S$. aureus in hospitalised children over three surveillance periods (8 weeks in total). While MSSA colonisation was common, no cases of MRSA colonisation were detected in 340 enrolled patients.

This is an important finding that is consistent with results from the previous reference study [6], where only 1 of 1363 patients tested in nine different Swiss children's hospitals was found to be colonised with MRSA. Hence, it can be concluded that there is no evidence that the prevalence of MRSA has increased during the 8.5 years which passed since the previous study was conducted under similar circumstances.

Of further interest is the prevalence of nasal MSSA colonisation, which was found to be $33 \%$. This proportion is lower compared to the previous study [6], where $41 \%$ of children were found to be colonised with MSSA. This difference might be explained by the multicentre nature of the earlier study and other variabilities such as age distribution. The previous study showed two age prevalence peaks among children 1-2 months of age as well as school-aged children. Other studies [1, 4, 8, 10, 23] examining the prevalence of $S$. aureus 
Fig. 1 Flow chart of the study process
Consented?

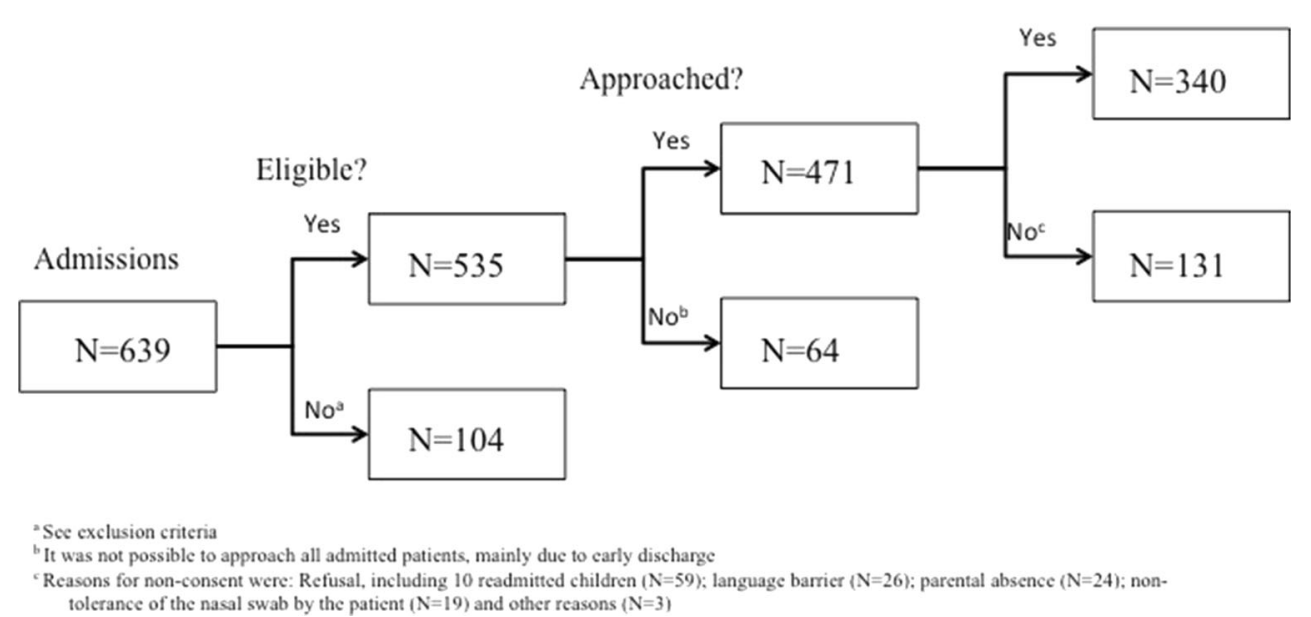

colonisation in children determined proportions ranging from $26-36 \%$, which is in line with our finding.

The age distribution of the patients participating in the study was fairly uniform in the age range from 2 to 16 years, with the highest number of participants less than 1 year old and second highest between 1 and 2 years old. The highest colonisation was found in 8-year-old patients, and in general, the colonisation was higher for children between 8 and 12 years as noted above. However, since numbers of study patients in the various age groups are limited, no firm conclusions can be drawn regarding a correlation between age and MSSA colonisation, but, these findings are in accordance with the previous study in Switzerland [6] and reports from the literature [1, 4, 10, 12].

As no patients with MRSA colonisation were found, data analyses were performed comparing patients with and without MSSA colonisation. The proportion of S. aureus colonisation was slightly higher in male patients compared to females; this was also the case in our previous Swiss wide study [6] and in other studies as well $[1,4,10,23]$; we have no explanation for this observation.

MSSA colonisation in patients on the surgical/orthopaedic ward was higher than in patients on the paediatric ward. When comparing at the age distribution of these children, it should be noted that the mean age of all enrolled children on the surgical/orthopaedic ward was 8.3 years, whereas it was 3.6 years for enrolled children on the paediatric ward. Similarly, the mean age of patients with nasal MSSA colonisation on the surgical/orthopaedic was 8.3 years versus 5.8 years on the paediatric ward. The implication of this is that the higher proportion of positive MSSA colonisation on the surgical/ orthopaedic ward probably is a direct result of the older age range of patients, as MSSA colonisation was higher in older

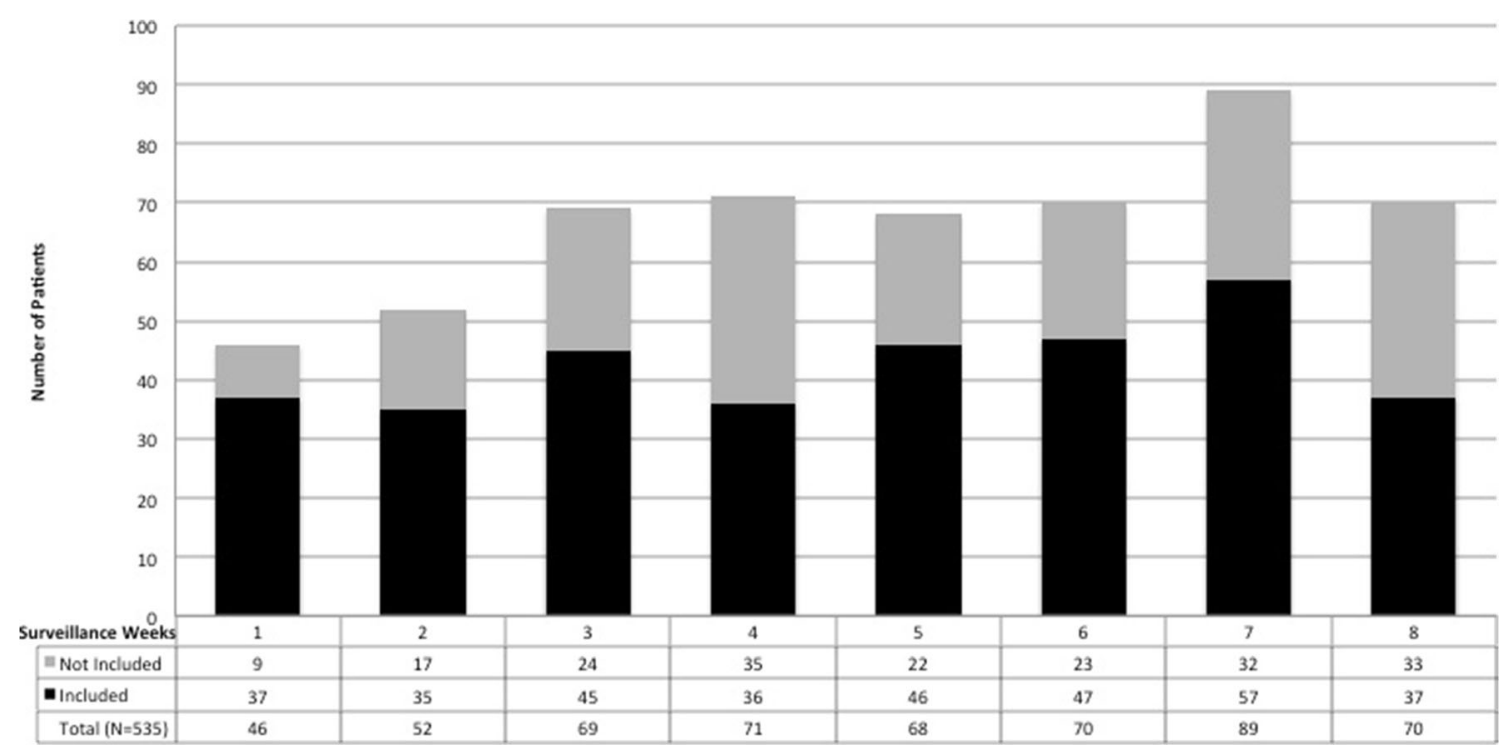

Fig. 2 Inclusion of eligible patients by surveillance weeks (surveillance weeks 1-4 correspond to calendar weeks 32-35 of 2014; surveillance weeks 5 and 6 to calendar weeks 45 and 46 of 2014; and surveillance weeks 7 and 8 to calendar weeks 6 and 7 of 2015) 


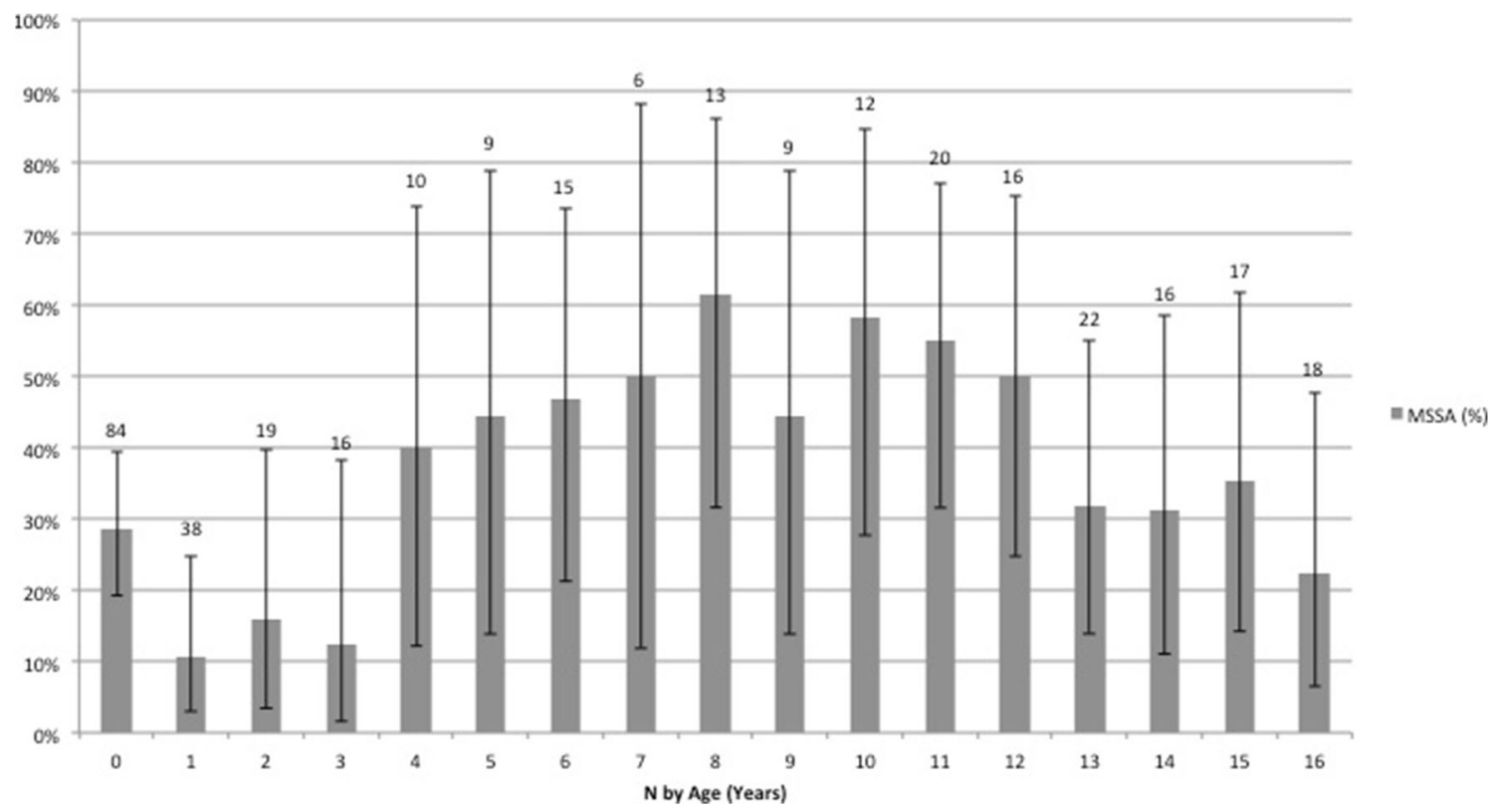

Fig. 3 Age distribution of study patients (with total $N$ by age group) and proportions colonised with MSSA; error bars denote $95 \%$ Clopper-Pearson confidence interval

children overall. It should be noted that the screening test was carried out on patients as they were admitted to the ward and hence placement on the ward itself cannot be a contributing factor to the differences in colonisation proportions. Would MRSA colonisation be a significant problem in our region, repeated screening tests on discharge of patients would be interesting with regards to nosocomial acquisition of carriage.

The proportion of MSSA colonisation was slightly higher in patients who own pets compared to those who don't. It is known that pets can be colonised with $S$. aureus [7, 18, 25], and hence it is plausible that pet ownership may increase the likelihood for colonisation in children. We further analysed these results taking age of the patients into account and found that pet owners colonised with MSSA were older than non-pet owners colonised with MSSA (mean age 8.5 years versus 6.5 years; IQR 5-12 years versus $0.25-11$ years). This result is in accordance with our general finding that older children have a higher proportion of nasal carriage with $S$. aureus.

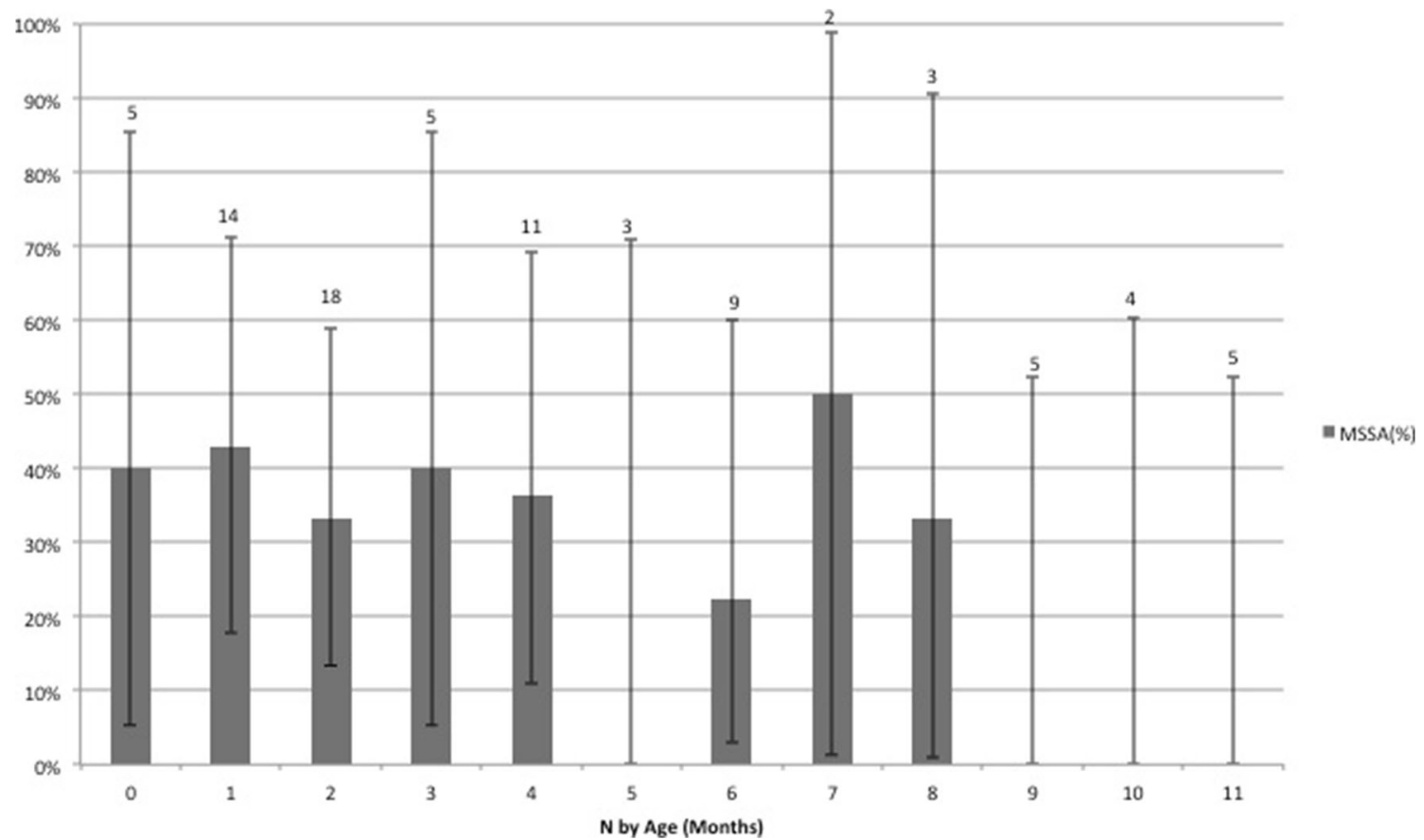

Fig. 4 Age distribution of study patients younger than 1 year (with total $N$ by age group) and proportions colonised with MSSA; error bars denote $95 \%$ Clopper-Pearson confidence interval 
Table 1 Patients characteristics and MSSA colonisation

\begin{tabular}{|c|c|c|c|c|}
\hline & \multirow{2}{*}{$\begin{array}{l}\text { Study patients } \\
(N=340) \\
N(\%)\end{array}$} & \multicolumn{2}{|c|}{ MSSA colonisation } & \multirow[t]{2}{*}{ Odds ratio $\left(95 \% \mathrm{CI}^{\mathrm{a}}\right.$} \\
\hline & & $\begin{array}{l}\text { Positive } \\
(N=111) \\
N(\%)\end{array}$ & $\begin{array}{l}\text { Negative } \\
(N=229) \\
N(\%)\end{array}$ & \\
\hline \multicolumn{5}{|l|}{ Sex } \\
\hline Male & $204(60)$ & $71(35)$ & $133(65)$ & $1.28(0.783-2.109)$ \\
\hline Female & $136(40)$ & $40(29)$ & $96(71)$ & Reference \\
\hline \multicolumn{5}{|l|}{ Domicile } \\
\hline $\mathrm{CH}$ & $316(93)$ & $104(33)$ & $212(67)$ & Reference \\
\hline FR & $13(4)$ & $4(31)$ & $9(69)$ & $0.91(0.201-3.367)$ \\
\hline DE & $5(1)$ & $0(0)$ & $5(100)$ & - \\
\hline Other & $6(2)$ & $3(50)$ & $3(50)$ & $2.04(0.275-15.843)$ \\
\hline \multicolumn{5}{|l|}{ Admission } \\
\hline From home & $332(98)$ & $107(32)$ & $225(68)$ & $0.48(0.087-2.610)$ \\
\hline From another hospital & $8(2)$ & $4(50)$ & $4(50)$ & Reference \\
\hline \multicolumn{5}{|l|}{ Pets } \\
\hline Yes & $129(38)$ & $49(38)$ & $80(62)$ & $1.47(0.901-2.398)$ \\
\hline No & $211(62)$ & $62(29)$ & $149(71)$ & Reference \\
\hline \multicolumn{5}{|c|}{$\begin{array}{l}\text { Stay abroad within } 3 \text { months } \\
\text { prior to admission }\end{array}$} \\
\hline Yes & $130(38)$ & $50(38)$ & $80(62)$ & $1.53(0.935-2.486)$ \\
\hline No & $210(62)$ & $61(29)$ & $149(71)$ & Reference \\
\hline \multicolumn{5}{|l|}{ Previous hospitalisations } \\
\hline Yes & $159(47)$ & $58(36)$ & $101(64)$ & $1.41(0.868-2.300)$ \\
\hline No & $173(51)$ & $50(29)$ & $123(71)$ & Reference \\
\hline Unknown & $8(2)$ & $3(38)$ & $5(62)$ & \\
\hline \multicolumn{5}{|c|}{$\begin{array}{l}\text { Hospitalisation within } 3 \text { months } \\
\text { prior to admission }\end{array}$} \\
\hline 0 & $292(86)$ & $96(33)$ & $196(67)$ & Reference \\
\hline 1 & $38(11)$ & $11(29)$ & $27(71)$ & $0.83(0.357-1.822)$ \\
\hline$>1$ & $6(2)$ & $2(33)$ & $4(67)$ & $1.02(0.091-7.265)$ \\
\hline Unknown & $4(1)$ & $2(50)$ & $2(50)$ & - \\
\hline \multicolumn{5}{|c|}{$\begin{array}{l}\text { Antibiotics within } 3 \text { months } \\
\text { prior to admission }\end{array}$} \\
\hline Yes & $72(21)$ & $19(26)$ & $53(74)$ & $0.7(0.368-1.293)$ \\
\hline No & $257(76)$ & $87(34)$ & $170(66)$ & Reference \\
\hline Unknown & $11(3)$ & $5(45)$ & $6(55)$ & - \\
\hline \multicolumn{5}{|l|}{ MRSA colonisation } \\
\hline Previously in patient & $1(0)$ & $0(0)$ & $1(100)$ & - \\
\hline In family & $1(0)$ & $0(0)$ & $1(100)$ & - \\
\hline \multicolumn{5}{|c|}{$\begin{array}{l}\text { Hospitalisation of family } \\
\text { member within } 3 \text { months } \\
\text { prior to admission }\end{array}$} \\
\hline Yes & $63(19)$ & $26(41)$ & $37(59)$ & $1.57(0.854-2.854)$ \\
\hline No & $275(81)$ & $85(31)$ & $190(69)$ & Reference \\
\hline Unknown & $2(1)$ & $0(0)$ & $2(100)$ & - \\
\hline \multicolumn{5}{|l|}{ Duration (days) } \\
\hline $0-5$ & $31(9)$ & $13(42)$ & $18(58)$ & - \\
\hline $6-10$ & $11(3)$ & $6(55)$ & $5(45)$ & - \\
\hline $11-20$ & $3(1)$ & $1(33)$ & $2(67)$ & - \\
\hline$>20$ & $7(2)$ & $1(14)$ & $6(86)$ & - \\
\hline
\end{tabular}


Table 1 (continued)

\begin{tabular}{|c|c|c|c|c|}
\hline & \multirow{2}{*}{$\begin{array}{l}\text { Study patients } \\
(N=340) \\
N(\%)\end{array}$} & \multicolumn{2}{|c|}{ MSSA colonisation } & \multirow[t]{2}{*}{ Odds ratio $\left(95 \% \mathrm{CI}^{\mathrm{a}}\right)$} \\
\hline & & $\begin{array}{l}\text { Positive } \\
(N=111) \\
N(\%)\end{array}$ & $\begin{array}{l}\text { Negative } \\
(N=229) \\
N(\%)\end{array}$ & \\
\hline Unknown & $13(4)$ & $5(38)$ & 8 & - \\
\hline \multicolumn{5}{|c|}{$\begin{array}{l}\text { Member of family working } \\
\text { in a medical institution }\end{array}$} \\
\hline Yes & $101(30)$ & $34(34)$ & $67(66)$ & $1.07(0.629-1.796)$ \\
\hline No & $239(70)$ & $77(32)$ & $162(68)$ & Reference \\
\hline \multicolumn{5}{|l|}{ Institution } \\
\hline Hospital & $45(13)$ & $10(22)$ & $35(88)$ & - \\
\hline Practise & $7(2)$ & $4(57)$ & $3(43)$ & - \\
\hline Old people's home & $19(6)$ & $7(37)$ & $12(63)$ & - \\
\hline Rehab & $2(1)$ & $0(0)$ & $2(100)$ & - \\
\hline Other & $24(7)$ & $10(42)$ & $14(58)$ & - \\
\hline Several & $4(1)$ & $3(75)$ & $1(25)$ & - \\
\hline
\end{tabular}

${ }^{\text {a }}$ Confidence interval

Colonisation proportion was slightly higher in children who had been hospitalised before in their life compared to those who had never been in hospital before. However, this difference was not statistically significant and no firm conclusions about a potential risk of nosocomial acquisition of MSSA colonisation should be drawn. Moreover, children who had been admitted to hospital for the first time were younger than children who were admitted at least once before. This is in line with the finding above that colonisation proportions are higher in older children.

There was a higher proportion of MSSA colonisation in children with a hospitalised family member in the 3 months prior to admission. Although not statistically significant, this data is in line with the previous study, where hospitalisation of a family member in the 3 previous months was described as an independent predictor for nasal colonisation with $S$. aureus [6].

Use of antibiotics in the 3 months prior to admission resulted in a trend for lower colonisation proportion. This has been shown before $[3,6,12]$ and was not affected by age or any of the other factors discussed above.

A further question we wanted to answer with this study was whether the current MRSA screening methods for patients admitted to the UKBB were adequate or if an enhanced, general screening would be necessary. The results show that although $50 \%$ of patients who were transferred from other hospitals were colonised with $S$. aureus, none of the isolates was MRSA. Furthermore, none of the few patients with a domicile in countries other than Switzerland, France or Germany were nasal carriers of MRSA. This implies that the current restrictive screening methods are very appropriate. In accordance with this, the disadvantages of screening such as costs but also psychological effects have recently been emphasised again [11].
The strengths of our study were its prospective nature; the broad case mix; and the very sensitive laboratory methods that were employed for detection of $S$. aureus colonisation. A limitation of our study was the small sample size. Hence, the power to test different hypotheses by multivariate analysis was limited and not appropriate. A further limitation was the inability to assess risk factors for MRSA colonisation as there were no cases detected. However, we were able to assess risk factors for MSSA.

In conclusion, the only two statistically significant risk factors for colonisation with MSSA were male sex and patients who have had at least one hospital stay before their current admission. From this information, we could infer that similar risk factors would be present for MRSA colonisation; however, there is no evidence for this. Periodic point prevalence surveillance of MRSA colonisation can guide hospital screening policies, and such studies are warranted in settings with low MRSA prevalence, like in many regions of Switzerland.

Acknowledgments The authors would like to acknowledge all participating patients as well as the staff of UKBB for their cooperation in conducting this study and especially for organising the test materials. The first author (KJ) would also like to acknowledge the laboratory staff of the Microbiology Laboratory, University Hospital Basel, for their assistance in carrying out the microbiologic investigations, and Timo Tondelli for assistance with statistical analyses.

Conflict of interest The authors declare that they have no conflict of interest.

Consent to participate statement All persons (parents and children, depending on age) gave their informed consent prior to their inclusion in the study.

Authors' contributions Kristen Johnson was the study coordinator and recruited all study patients, conducted interviews to collect the data, 
performed nasal swabs and the microbiological investigations, carried out all data analyses, drafted the manuscript, and approved the final manuscript as submitted. Reno Frei contributed to concept and design of the study, supervised the microbiological investigations, reviewed and revised the manuscript, and approved the final manuscript as submitted. Ulrich Heininger conceptualized and designed the study, supervised patient recruitment, data collection and analyses, critically reviewed the draft manuscript, and approved the final manuscript as submitted.

\section{References}

1. Bogaert D, van Belkum A, Sluijter M, Luijendijk A, de Groot R, Rumke HC, Verbrugh HA, Hermans PW (2004) Colonisation by Streptococcus pneumoniae and Staphylococcus aureus in healthy children. Lancet 363:1871-1872. doi:10.1016/S0140-6736(04)16357-5

2. Centers for Disease C, Prevention (2003) Outbreaks of communityassociated methicillin-resistant Staphylococcus aureus skin infections-Los Angeles County, California, 2002-2003. MMWR Morb Mortal Wkly Rep 52:88

3. Chen CJ, Hsu KH, Lin TY, Hwang KP, Chen PY, Huang YC (2011) Factors associated with nasal colonization of methicillin-resistant Staphylococcus aureus among healthy children in Taiwan. J Clin Microbiol 49:131-137. doi:10.1128/JCM.01774-10

4. Ciftci IH, Koken R, Bukulmez A, Ozdemir M, Safak B, Cetinkaya Z (2007) Nasal carriage of Staphylococcus aureus in 4-6 age groups in healthy children in Afyonkarahisar, Turkey. Acta Paediatr 96:1043-1046. doi:10.1111/j.1651-2227.2007.00315.x

5. Creech CB 2nd, Kernodle DS, Alsentzer A, Wilson C, Edwards KM (2005) Increasing rates of nasal carriage of methicillinresistant Staphylococcus aureus in healthy children. Pediatr Infect Dis J 24:617-621

6. Datta F, Erb T, Heininger U, Gervaix A, Schaad UB, Berger C, Vaudaux B, Aebi C, Hitzler M, Kind C, Gnehm HE, Frei R, Pediatric Infectious Disease Group Switzerland MethicillinResistant Staphylococcus aureus Study G (2008) A multicenter, cross-sectional study on the prevalence and risk factors for nasal colonization with Staphylococcus aureus in patients admitted to children's hospitals in Switzerland. Clin Infect Dis : Off Public Infect Dis Soc Am 47:923-926. doi:10.1086/591700

7. Davis JA, Jackson CR, Fedorka-Cray PJ, Barrett JB, Brousse JH, Gustafson J, Kucher M (2014) Carriage of methicillin-resistant staphylococci by healthy companion animals in the US. Lett Appl Microbiol 59:1-8. doi:10.1111/lam.12254

8. Dey S, Rosales-Klintz S, Shouche S, Pathak JP, Pathak A (2013) Prevalence and risk factors for nasal carriage of Staphylococcus aureus in children attending anganwaries (preschools) in Ujjain, India. BMC Res Notes 6:265. doi:10.1186/1756-0500-6-265

9. Diekema DJ, Pfaller MA, Schmitz FJ, Smayevsky J, Bell J, Jones RN, Beach M, Group SP (2001) Survey of infections due to Staphylococcus species: frequency of occurrence and antimicrobial susceptibility of isolates collected in the United States, Canada, Latin America, Europe, and the Western Pacific region for the SENTRY Antimicrobial Surveillance Program, 1997-1999. Clin Infect Dis : Off Public Infect Dis Soc Am 32(Suppl 2):S114 S132. doi:10.1086/320184

10. Esposito S, Terranova L, Zampiero A, Ierardi V, Rios W, Pelucchi C, Principi N (2014) Oropharyngeal and nasal Staphylococcus aureus carriage by healthy children. BMC Infect Dis 14:3844. doi:10. 1186/s12879-014-0723-9

11. Fatkenheuer G, Hirschel B, Harbarth S (2015) Screening and isolation to control meticillin-resistant Staphylococcus aureus: sense, nonsense, and evidence. Lancet 385:1146-1149. doi:10.1016/ S0140-6736(14)60660-7
12. Gesualdo F, Onori M, Bongiorno D, Campanile F, Carloni E, Mancinelli L, Russo C, Villani A, Valentini D, Raponi M, Tozzi AE, Stefani S (2014) Methicillin-resistant Staphylococcus aureus nasal colonization in a department of pediatrics: a cross-sectional study. Ital J Pediatr 40:3. doi:10.1186/1824-7288-40-3

13. Heininger U, Datta F, Gervaix A, Schaad UB, Berger C, Vaudaux B, Aebi C, Hitzler M, Kind C, Gnehm HE, Frei R, Group PMS (2007) Prevalence of nasal colonization with methicillin-resistant Staphylococcus aureus (MRSA) in children a multicenter crosssectional study. Pediatr Infect Dis J 26:544-546. doi:10.1097/INF. 0b013e31804d244a

14. Herold BC, Immergluck LC, Maranan MC, Lauderdale DS, Gaskin RE, Boyle-Vavra S, Leitch CD, Daum RS (1998) Communityacquired methicillin-resistant Staphylococcus aureus in children with no identified predisposing risk. Jama 279:593-598

15. Jevons MP, Coe AW, Parker MT (1963) Methicillin resistance in staphylococci. Lancet 1:904-907

16. Larsson AK, Gustafsson E, Johansson PJ, Odenholt I, Petersson AC, Melander E (2014) Epidemiology of MRSA in southern Sweden: strong relation to foreign country of origin, health care abroad and foreign travel. Europ J Clin Microbiol Infect Dis : Off Public Europ Soc Clin Microbiol 33:61-68. doi:10.1007/s10096-013-1929-2

17. Lo WT, Wang CC, Lin WJ, Wang SR, Teng CS, Huang CF, Chen SJ (2010) Changes in the nasal colonization with methicillinresistant Staphylococcus aureus in children: 2004-2009. PLoS One 5:e15791. doi:10.1371/journal.pone.0015791

18. Misic AM, Davis MF, Tyldsley AS, Hodkinson BP, Tolomeo P, Hu B, Nachamkin I, Lautenbach E, Morris DO, Grice EA (2015) The shared microbiota of humans and companion animals as evaluated from Staphylococcus carriage sites. Microbiomedicines 3:2. doi:10. 1186/s40168-014-0052-7

19. Naimi TS, LeDell KH, Como-Sabetti K, Borchardt SM, Boxrud DJ, Etienne J, Johnson SK, Vandenesch F, Fridkin S, O'Boyle C, Danila RN, Lynfield R (2003) Comparison of community- and health care-associated methicillin-resistant Staphylococcus aureus infection. Jama 290:2976-2984. doi:10.1001/jama.290.22.2976

20. Otto M (2014) Staphylococcus aureus toxins. Curr Opin Microbiol 17:32-37. doi:10.1016/j.mib.2013.11.004

21. Panlilio AL, Culver DH, Gaynes RP, Banerjee S, Henderson TS, Tolson JS, Martone WJ (1992) Methicillin-resistant Staphylococcus aureus in U.S. hospitals, 1975-1991. Infect Control Hosp Epidemiol 13:582-586

22. Saravolatz LD, Pohlod DJ, Arking LM (1982) Communityacquired methicillin-resistant Staphylococcus aureus infections: a new source for nosocomial outbreaks. Ann Intern Med 97:325-329

23. Soltani B, Taghavi Ardakani A, Moravveji A, Erami M, Haji Rezaei M, Moniri R, Namazi M (2014) Risk factors for methicillin resistant Staphylococcus aureus nasal colonization of healthy children. Jundishapur J Microbiol 7:e20025. doi:10.5812/jjm.20025

24. Tiemersma EW, Bronzwaer SL, Lyytikainen O, Degener JE, Schrijnemakers P, Bruinsma N, Monen J, Witte W, Grundman H, European Antimicrobial Resistance Surveillance System P (2004) Methicillin-resistant Staphylococcus aureus in Europe, 1999-2002. Emerg Infect Dis 10:1627-1634. doi:10.3201/eid1009.040069

25. Vincze S, Stamm I, Kopp PA, Hermes J, Adlhoch C, Semmler T, Wieler LH, Lubke-Becker A, Walther B (2014) Alarming proportions of methicillin-resistant Staphylococcus aureus (MRSA) in wound samples from companion animals, Germany 2010-2012. PLoS One 9:e85656. doi:10.1371/journal.pone.0085656

This work is the master thesis of Kristen Johnson at the Medical Faculty of the University Basel, Switzerland. 